\title{
NGS-guided precision oncology in metastatic breast and gynecological cancer: first experiences at the CCC Munich LMU
}

\author{
Elena Sultova ${ }^{1}$ - C. Benedikt Westphalen ${ }^{2}$. Andreas Jung ${ }^{3}$. Joerg Kumbrink ${ }^{3}$ - Thomas Kirchner ${ }^{3}$ - Doris Mayr ${ }^{3}$. \\ Martina Rudelius $^{3}$. Steffen Ormanns ${ }^{3}$. Volker Heinemann ${ }^{2}$ - Klaus H. Metzeler ${ }^{2}$. Philipp A. Greif ${ }^{2}$. \\ Alexander Burges $^{1,4} \cdot$ Fabian Trillsch $^{1,4} \cdot$ Sven Mahner ${ }^{1,4} \cdot$ Nadia Harbeck $^{1,5} \cdot$ Rachel Wuerstlein $^{1,4,5}$
}

Received: 14 August 2020 / Accepted: 4 November 2020 / Published online: 4 December 2020

(c) The Author(s) 2020

\begin{abstract}
Purpose Comprehensive genomic profiling identifying actionable molecular alterations aims to enable personalized treatment for cancer patients. The purpose of this analysis was to retrospectively assess the impact of personalized recommendations made by a multidisciplinary tumor board (MTB) on the outcome of patients with breast or gynecological cancers, who had progressed under standard treatment. Here, first experiences of our Comprehensive Cancer Center Molecular Tumor Board are reported.

Methods All patients were part of a prospective local registry. 95 patients diagnosed with metastatic breast cancer or gynecological malignancies underwent extended molecular profiling. From May 2017 through March 2019, the MTB reviewed all clinical cases considering tumor profile and evaluated molecular alterations regarding further diagnostic and therapeutic recommendations.

Results 95 patients with metastatic breast or gynecological cancers were discussed in the MTB (68\% breast cancer, $20 \%$ ovarian cancer, $5 \%$ cervical cancer, $3 \%$ endometrial cancer and $4 \%$ others). Genes with highest mutation rate were PIK3CA and ERBB2. Overall, 34 patients (36\%) received a biomarker-based targeted therapy recommendation. Therapeutic recommendations were implemented in nine cases; four patients experienced clinical benefit with a partial response or disease stabilization lasting over 4 months.

Conclusion In the setting of a multidisciplinary molecular tumor board, a small but clinically meaningful group of breast and gynecological cancer patients benefits from comprehensive genomic profiling. Broad and successful implementation of precision medicine is complicated by patient referral at late stage disease and limited access to targeted agents and early clinical trials.
\end{abstract}

Trial registration number 284-10 (03.05.2018).

Keywords Personalized medicine $\cdot$ Breast cancer $\cdot$ Ovarian cancer $\cdot$ Biomarker $\cdot$ Molecular diagnostic $\cdot$ Molecular tumor board

Rachel Wuerstlein

Rachel.Wuerstlein@med.uni-muenchen.de

1 Department of Obstetrics and Gynecology and CCC Munich LMU University Hospital, Ludwig Maximilians University (LMU), Munich, Germany

2 Department of Internal Medicine III and CCC Munich LMU, University Hospital, Ludwig Maximilians University (LMU), Munich, Germany
3 Institute of Pathology and CCC Munich LMU, University Hospital, Ludwig Maximilians University (LMU), Munich, Germany

4 Gynecologic Oncology Center and CCC Munich LMU University Hospital, Ludwig Maximilians University (LMU), Munich, Germany

5 Breast Center and CCC Munich LMU University Hospital, Ludwig Maximilians University (LMU), Munich, Germany 


\section{Introduction}

In women, metastatic breast cancer and gynecological malignancies are among the most frequent causes of cancer death. In 2018, there were an estimated 2,088,849 new cases of breast cancer and 626,679 deaths, 569,847 new cases of cervical cancer and 311365 deaths, and 295,414 new cases of ovarian cancer and 184,799 deaths worldwide. [1] Despite rising overall incidence, mortality rate has steadily decreased owing to early detection and improvements in the therapeutic management of these patients. However, although the development of new drugs, vaccines, and systematic screening programs has improved patients' outcomes, effective measures to successfully treat metastatic cancer are still missing.

With the advent of molecular diagnostics, cancer treatment entered a new era. New techniques of sequencing DNA such as comprehensive genomic profiling (CGP) and hotspot next generation sequencing (NGS) provide tools for deciphering complete genes and later entire genomes at unprecedented speed [2]. These new approaches led to the development of a novel cancer treatment movement, known as precision medicine. By selecting the most effective treatment based on the molecular characteristics of tumor tissues or some other biologic parameters of the malignant disease, precision medicine aims to offer personalized treatment concepts to cancer patients with limited standard of care options. Molecular therapeutic agents (MTA) targeting individual actionable molecular alterations have been successfully developed in the past few years, showing the positive impact of using molecular-based therapy on the cancer patients' outcome [3-6]. These include the use of growth factor receptor 2 antibody trastuzumab in breast cancer, a tyrosine kinase inhibitor imatinib in myelogenous leukemia associated with the BCR-ABL fusion gene and EGFR tyrosine kinase inhibitors in lung carcinomas $[7,8]$.

Breast and gynecological cancers constitute a heterogeneous group of malignant diseases associated with multiple genetic alterations [9-11]. In the past few years, a growing number of molecular markers in breast cancer, for example, have been investigated and some of them are now well-established as reliable predictors of prognosis and response to tumor therapy (Fig. 1a). Moreover, many different targeted therapies have been approved for use in breast cancer treatment (Fig. 1b). The recent approval of the PIK3CA specific inhibitor alpelisib has been the most recent example of targeted agents moving into routine care. [12] Treatment with alpelisib was shown to prolong PFS by more than 6 months compared to the control arm. [13]

In gynecologic malignancies, MTAs have also been successfully implemented into clinical care. For example, early data from a clinical phase II trial focusing on BRCAmutated ovarian cancer showed that olaparib as maintenance treatment significantly improved progression-free survival (PFS) in relapsed platinum-sensitive ovarian cancer [15]. In 2018, these data could be transferred to the first line setting when treatment effects of the SOLO1 trial were presented [16]. Due to an impressive PFS improvement and a 70\% lower risk of disease progression or death with olaparib compared to placebo, this effect led to the incorporation of PARP inhibitors into the primary treatment of ovarian cancer in 2019 [17]. However, when it comes to other gynecologic malignancies such as endometrial cancer, the development of MTA is delayed in comparison to other malignancies.

By detecting potential actionable pathways using molecular diagnostics, it is also possible to assess and treat various cancer types. For example, the ERBB2/PIK3/ AKT/mTOR pathway is known for its relevance in breast cancer, but recently a relevant actionable mutation from the same pathway, PIK3R $1^{\text {W624R }}$ was also identified in ovarian cancer [18]. Another study suggested that some subtypes of cervical cancers may also benefit from existing ERBB2/PIK3/AKT/mTOR targeted agents [19].

With the rising number of MTAs and considering the heterogeneous molecular profiles of breast cancer and gynecological malignancies, it is reasonable to expect that patients with these malignancies could potentially benefit from implementation of precision oncology based on comprehensive genomic profiling (CGP) into clinical care. Promising early data for such malignancies has been presented in multiple trials. In breast cancer, many reports of such driver alterations have emerged in the past few years, suggesting that patients could profit from precision medicine and targeted therapies [20]. For example, in the SAFIR01 multicenter prospective trial, data of precision medicine benefitting breast cancer patients were presented. 9 out of 43 patients (21\%) responded to the recommended targeted therapy with a stable disease lasting over 16 weeks [21]. In ovarian cancer, multiplatform molecular profiling, conducted in a commercially available profiling center, led to a significantly longer post-profiling survival in patients, who were treated with profile-guided targeted agents, in comparison to the control group [22].

With the technical advances in molecular diagnostics and the continuous approval of many targeted therapies, the growing field of precision medicine is constantly expanding and requires optimization. Considering the complexity of precision medicine in oncology, it was reasonable to create a molecular tumor board (MTB) to leverage the knowledge of the many different disciplines involved in oncological treatment and to provide optimal treatment recommendations. In this manuscript, first 
Fig. 1 Predictive factors (a) and treatment-relevant genetic alterations (b) in metastatic breast cancer, German Gynecological Oncology Group. In 2018, AGO was the first international guideline-commission to make recommendations regarding precision medicine in breast cancer. (http://www.ago-onlin e.de) [14]

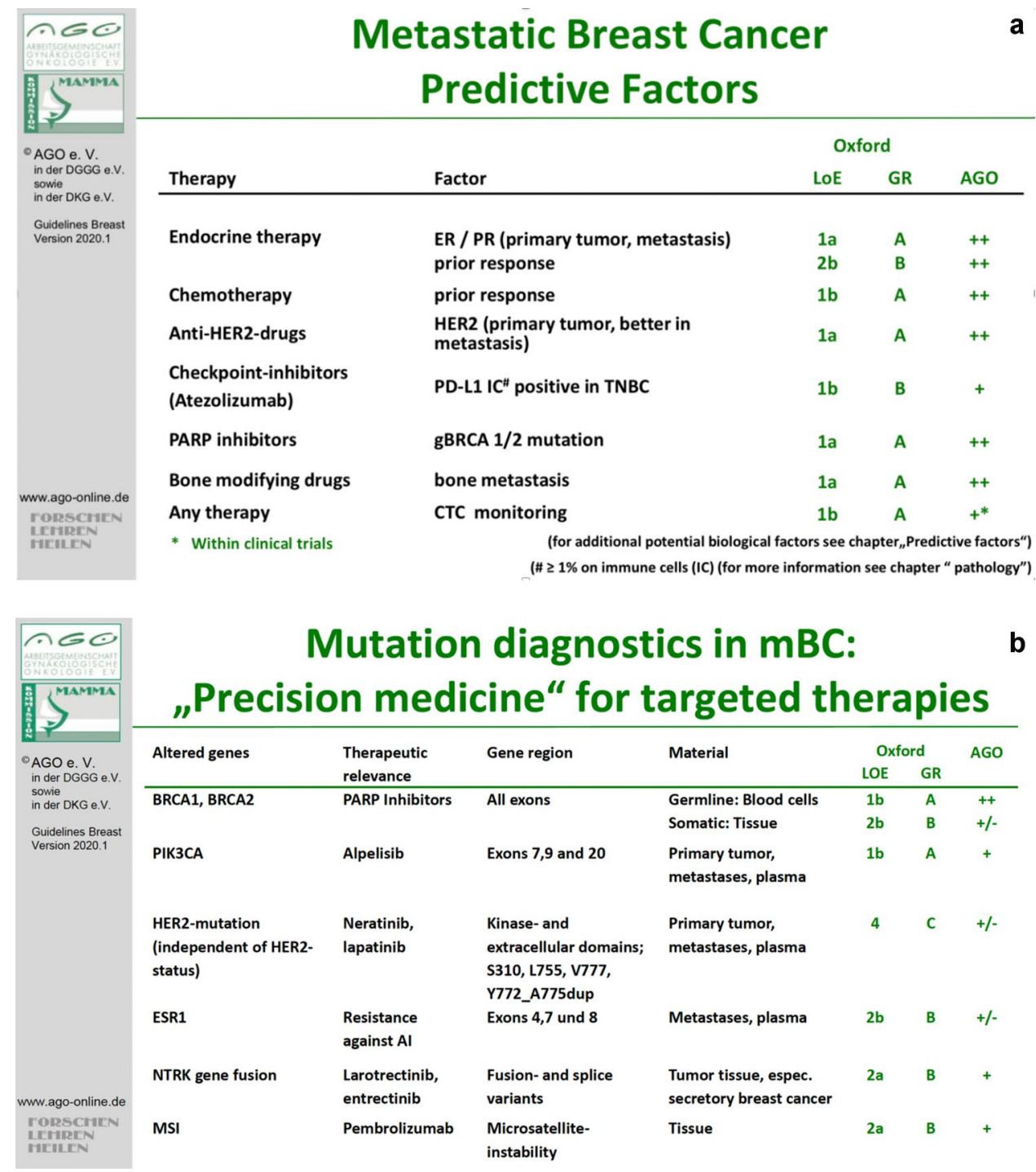

experiences of the Comprehensive Cancer Center (CCC) LMU Munich Molecular Tumor Board are presented.

The aim of this project was to retrospectively measure the impact of MTB discussions and recommendations made by a multidisciplinary tumor board on outcome of patients with breast and gynecological cancers progressing under standard treatment. Detailed information including data on patient characteristics, diagnostic and treatment recommendations, implementation of the recommendations, and outcome of treated patients with breast and gynecological cancers (ovarian, endometrial, cervix, and other type of cancer) are presented.

\section{Materials and methods}

All patients reported here were discussed in the local MTB, which reviewed clinical cases and the respective tumor profiles with the associated actionable alterations. The final result of each MTB case discussion was a report, focused on NGS data and diagnostic and potential diagnostic, and therapeutic alternatives. Thereby, the MTB presented itself as a multidisciplinary team (MDT), which comprised clinical oncologists, pathologists, molecular pathologists, genetic counselors, bioinformaticians, and scientists with expertise in genetic and tumor profiling in diverse cancers. MTB-meetings were held every 2 weeks with the purpose of interpretation and/or translation of the molecular diagnostics' results into diagnostic and/or treatment recommendations. All patients' cases were first presented at organspecific gynecology tumor boards by a team of experienced gyneco-oncologists, who reviewed all the clinical course of every individual patient and discussed if patients were eligible for a MTB discussion. Apart from recent tumor material, recent radiology images and other diagnostic tests were also required for the interdisciplinary setting of the MTB. All treatment recommendations were supported by levels of 
evidence by using the ESMO Scale for Clinical Actionability of molecular Targets (ESCAT). The process from enrolling the patient into the study till receiving a recommendation by the MTB is shown in Fig. 2.

\section{Patients and patient informed consent}

All patients discussed $(n=95)$ were included in the prospective single-center case study, "The informative Patient", launched in March 2017 at the LMU University Hospital, Munich as a Munich-site part of the DKTK (German Cancer Consortium) program. All enrolled patients suffered from metastatic breast or gynecological cancer which had progressed after at least one line of prior standard treatment and who had no longer access to curative treatment. Prior to inclusion, all participants signed an informed consent that they were informed about potential and limitations that molecular diagnostics could offer for treatment selection and for analysis of their data, further discussion of their case by a multidisciplinary MTB, as well as for collecting follow-up data on the course of disease for research purpose (including requesting patient data from other physicians and institutions).

The intention-to-treat (ITT) population consisted of 100 patients. Eventually, five patients were excluded, because of death prior to a treatment recommendation or withdrawal of consent.

The data here are based on the results of an ITT population of 95 patients.

\section{Molecular pathology}

Molecular analyses were performed at the Institute of Pathology of the LMU. Appropriate tissue regions were selected histo-morphologically from formalin-fixed paraffin embedded (FFPE)- or fresh frozen tissue. Moreover, liquid biopsies (blood, liquor) were included. In only four patients, analysis had to be repeated due to material constraints. Targeted NGS was performed with the Oncomine Comprehensive Cancer v.3 Panels (Agilent) thereby screening for changes in 161 genes on DNA (SNV, MNV, small ins, del, indels, CNV) and RNA (gene fusions) level. DNA and RNA were isolated using Qiagen's GeneRead DNA FFPE- or RNeasy FFPE-kits, respectively. Nucleic acids (NA; DNA, and RNA) from liquid biopsies were prepared by utilization of the QIAamp Circulating Nucleic Acid Kit. Subsequently, library preparation as first step of NGS was generated by employing Ampliseq Library Plus-, Ampliseq cDNA synthesis-, Ampliseq CD index, Ampliseq Equalizer- together with Ampliseq Comprehensive v3-kits (all Illumina) or DNA- and RNA-Oncomine Comprehensive Panels v3 and Ion AmpliSeq Library-, IonXpress Barcode Adapter-, Ion Library Equalizer-kits together with Ion Chip kits (mostly 550) (all Thermo Fisher), following for each step the respective user manuals. Libraries were run on an Ion Torrent GeneStudio S5 Primer (Thermo Fisher) or Illumina 500 Next Seq (Illumina) NGS machine. Analysis of results was performed with either the Ion-Reporter System (Thermo Fisher) followed by further variant and quality interpretation with a self-made excel tool or annotating

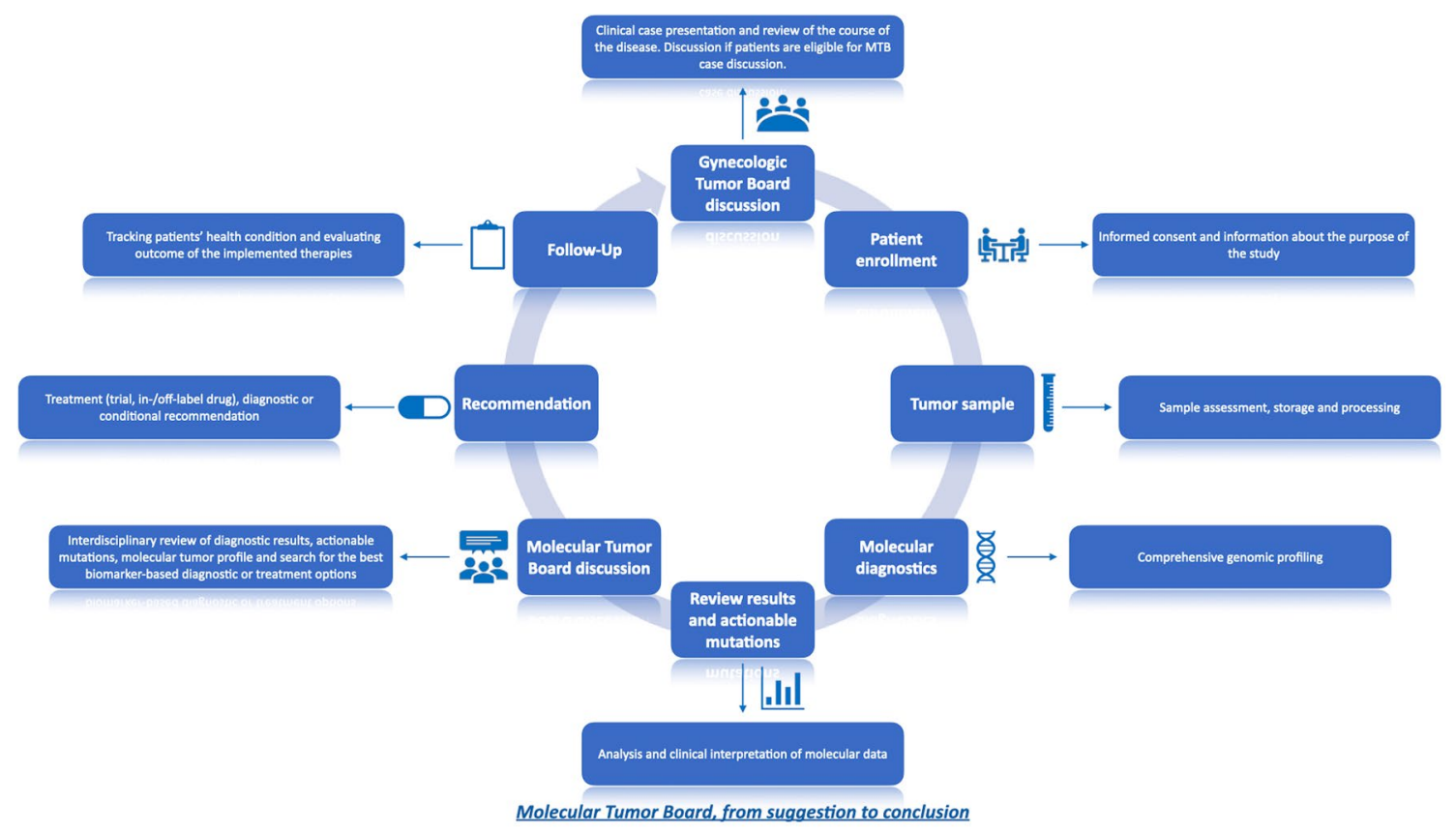

Fig. 2 MTB, from suggestion to conclusion 
VCF-files using wAnnovar (http://wannovar.wglab.org/) [23] together with the self-made python-script PathoMine filtering for clinically relevant mutations. Mutations were judged as relevant on the basis of the key 'interpretation' given in ClinVar [24]. Alterations were confirmed with the Integrated Genomics Viewer (IGV, Broad Institute). The resulting molecular pathological dataset together with data from immunohistochemistry, fluorescence in situ hybridization (FISH), and histo-morphology became part of a comprehensive pathological report which was sent out to the MTB.

\section{Data assessment}

For this analysis, electronic medical records were reviewed for patient characteristics and follow-up. If needed, medical oncologists, gynecologists, and general practitioners were contacted in order to collect follow-up data on treatment course and patient status. Patient characteristics were summarized using descriptive statistics. Follow-up of clinical outcomes was performed to track tumor response to recommended therapies and analyzed by measuring progressionfree survival (PFS) of patients, who received the recommended treatment. PFS was calculated from the first day of treatment with the recommended in- or off-label targeted drug until the date of disease progression or death, whichever occurred first, analogous to the Johns Hopkins MTB study and to the Von Hoff et al. study [25]. In order to evaluate the benefit of the treatment recommendation, we then calculated the PFS ratio (PFSr) by comparing the PFS of the recommended treatment and the PFS of the previous therapy of the patients. Cut-off date for data analysis was August 1st, 2019.

\section{Results}

\section{Patient characteristics}

From March 2017 through March 2019, a total of 95 cases were submitted to the MTB. All patients $(n=95)$ were females, had an underlying malignant condition, suffered from metastatic disease, and had experienced disease progression under standard treatment. Patients with implemented therapy recommendations had received a median of five (range 2-6) prior therapies for metastatic cancer. The median age at time of the initial MTB presentation was 52 years (range $19-82$ years).

As shown in Fig. 3, the most frequent tumor type was breast cancer $(n=64,68 \%)$, followed by ovarian cancer $(n=19,20 \%)$. The majority of patients with breast cancer had triple-negative (ER, PR and HER2 negative; $n=30$; $46.9 \%$ ), followed by estrogen receptor (ER) -positive and/ or progesterone receptor (PR) -positive, human epidermal growth factor receptor 2 (HER2) -negative (luminal-like) $(\mathrm{n}=28 ; 43.8 \%)$, or HER2 positive, ER-negative, PR-negative disease $(\mathrm{n}=5 ; 7.8 \%)$ at the time of the MTB case discussion;
Fig. 3 Distribution of the cases discussed at the MTB meeting by tumor entity $(n=95)$

\section{Patient distribution}

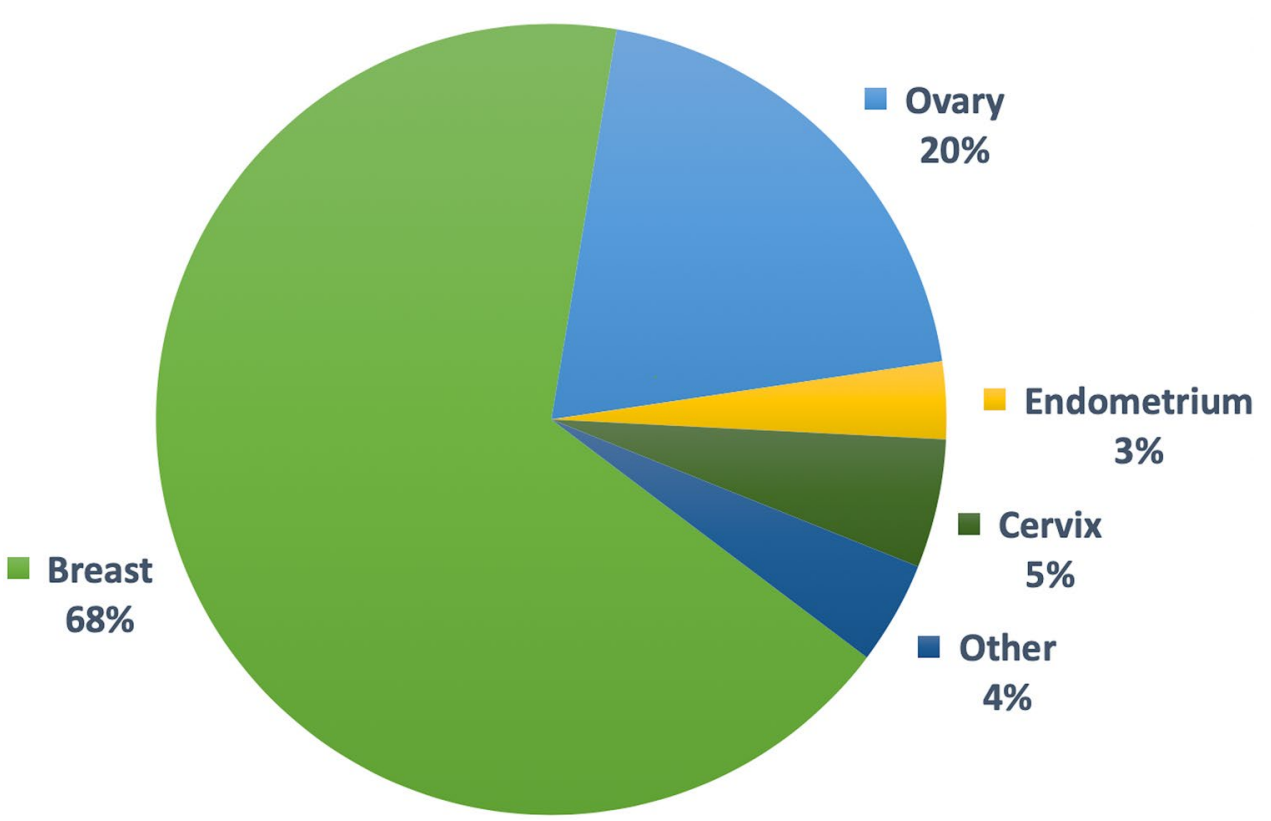


one patient (1.6\%) had triple-positive disease (ER positive and/or PR positive, HER2 positive).

Characteristics of patients with a molecular profile are reported in Table 1.

Table 1 Patient characteristics

\begin{tabular}{ll}
\hline Covariables & \\
\hline $\begin{array}{l}\text { Median age at diagnosis } \\
\text { Age at diagnosis }\end{array}$ & 47 years (range 12-80) \\
$<30$ & $5(5.3 \%)$ \\
$30-39$ & $27(28.4 \%)$ \\
$40-49$ & $21(22.1 \%)$ \\
$50-59$ & $30(31.6 \%)$ \\
$60-69$ & $8(8.4 \%)$ \\
$\geq 70$ & $4(4.2 \%)$ \\
Median age at MTB case presentation & 52 years (range 19-82) \\
Age at MTB case presentation & \\
$<30$ & $2(2.1 \%)$ \\
$30-39$ & $19(20.0 \%)$ \\
$40-49$ & $20(21.1 \%)$ \\
$50-59$ & $28(29.5 \%)$ \\
$60-69$ & $18(18.9 \%)$ \\
$\geq 70$ & $8(8.4 \%)$ \\
\hline
\end{tabular}

\section{Molecular profiling}

Molecular tests using NGS were performed for all 95 patients. Out of the set of mutations from the molecular pathological NGS-analysis, actionable mutations were defined as those matching or informing the use of available targeted agents.

Four patients had tumor sequencing performed twice during the course of disease. $81(85.3 \%)$ patients had suitable tissues for multimodal molecular profiling (NGS). All in all, 103 molecular alterations were identified in 55 cases $(57.9 \%)$. The median number of alterations observed in each sample was one (range 0-6). Out of the 55 patients, $41(43.2 \%)$ had an actionable mutation, which the board reviewed as a potentially targetable. No genomic alterations in the 161 investigated genes were found in $40(42.1 \%)$ analyses, in $14(14.7 \%)$ of which the molecular diagnostics test was technically not successful because of poor DNA quality or insufficient material quality. Although five (5.3\%) patients had an actionable mutation, they did not receive a therapy recommendation because of co-morbidities, not meeting trial inclusion criteria, or other requirements for receiving a specific targeted therapy.

We discovered mutations in over 30 different genes. Among the patients tested, the most common alterations were as follows: PIK3CA mutation (13/95; 13.7\%); ERBB2 mutation (10/95; 10.5\%); KRAS mutation (9/95; 9.5\%), and CCND1 mutation (9/95; 9.5\%). Incidences of

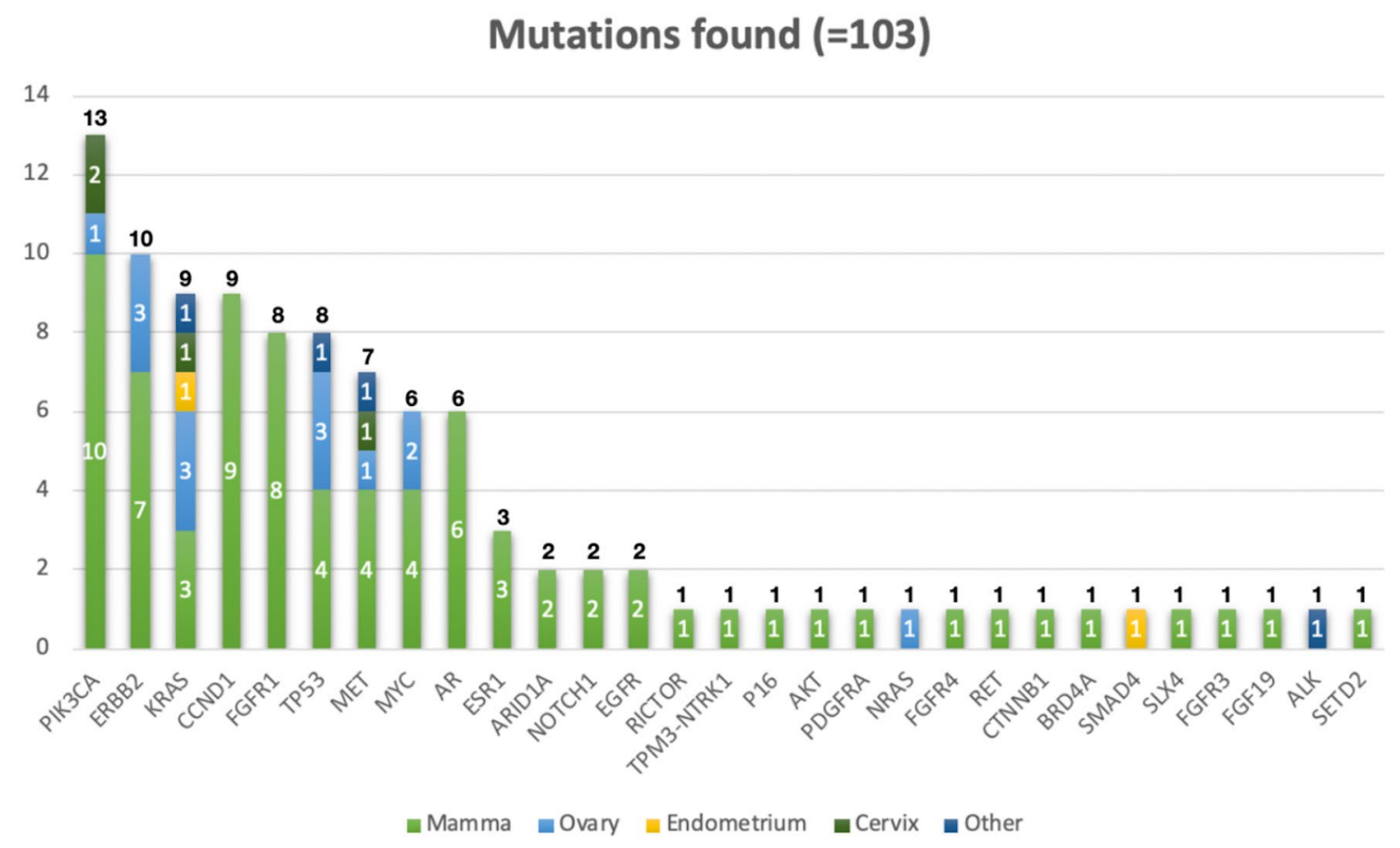

Fig. 4 Frequency of genomic alterations for the different tumor entities $(n=95)$ 
genomic alterations by gene and the distribution of molecular alterations by tumor type are shown in Fig. 4 .

\section{Recommendations}

Among the 55 (57.9\%) patients with at least one molecular alteration identified, 41 patients (43.2\%) had an actionable alteration, whereas 14 (14.7\%) had only non-actionable variants. Eventually, this resulted in 15 diagnostic and 49 treatment recommendations for 45 patients (47.4\%). Multiple recommendations were adjusted for $20(21.1 \%)$ patients (multiple recommendation principle). Six patients received a conditional recommendation, which required specific further diagnostics, two of which resulted in a treatment recommendation.

\section{Diagnostic recommendations}

Out of 15 diagnostic recommendations, 10 were pursued. In seven $(7.4 \%)$ cases, extended genetic analyses were recommended and eventually six $(6.3 \%)$ of them were performed. Re-biopsies were recommended in 14 cases, when the initial diagnostic tests were technically not successful, which we did not include in the evaluation of the final results.

\section{Therapeutic recommendations}

As shown in Fig. 5, 36 (37.9\%) patients were given a therapy recommendation, $14(14.7 \%)$ of whom received more than one treatment suggestion, as their tumor molecular profile revealed more than one actionable mutation. Two (2.1\%) patients were excluded from the evaluation of the clinical outcome, as they received the recommended therapy in the period between NGS analysis and MTB treatment recommendation.

Overall, 9 of 34 therapeutic recommendations were pursued. Of note, in the present cohort, no patient pursued the recommended enrollment in a clinical trial. In-label therapy recommendations were implemented in five cases, whereas off-label recommendations were implemented in four patients. The most common reasons for non-administration of MTB-recommended therapy were deterioration of patients' physical health condition, early death, no access to the recommended drug therapy, declined reimbursement applications by payer, or patient decision (see Table 2).

\section{Clinical outcome}

All patients were included in the registry after multiple standard of care treatments.

Out of nine $(9.5 \%)$ patients following therapy recommendation, 4 (4.2\%) showed a state of partial remission or stabilization lasting more than 16 weeks, including two of them receiving off-label therapy recommendation. Comparing PFS of the recommended therapy with the PFS of the previously received systemic treatment, we estimated that four of nine responders receiving MTB-recommended therapies displayed a progression-free survival (PFS) ratio (PFS2/ PFS1; PFSr) $>1.3$, showing the relevance of the suggested therapies. Two patients responded with an ongoing PFSr. Figure 6 details the actual comparison of PFS on implemented recommended treatment versus PFS on the patient's last prior treatment.

More information about the outcome of responding patients is shown in Table 3.

See Appendix for details of identified actionable mutations and corresponded treatment recommendations made by the MTB.

\section{Discussion}

We evaluated the clinical consequences of actionable genetic alterations (by NGS) in 95 patients with metastatic breast cancer and gynecological malignancies, part of a pilot monocentric patient registry with the purpose of generating real-world data. Forty-one patients $(43.2 \%)$ had at least one actionable molecular aberration. The total number of patients with a drug-targetable alteration was 34 (35.7\%). Overall, 9 of 34 patients (9.5\% of all) received the recommended drug treatment. In a small, but significant group of patients, four out of nine with implemented therapy recommendations $(44.4 \%)$ experienced a clinical benefit (PFSr $>1.3$ ) lasting over 16 months, a result similar to the one shown by Jameson et al. in cases of patients with metastatic breast cancer, who received personalized therapy recommendations based on multi-omic molecular profiling [26, 27].

Precision medicine offers not only personalized treatment concepts for patients, but also helps us optimize diagnostic and treatment options by identifying biomarkers that are linked to response and resistance to immunotherapy. For instance, in the past few years, the problem of resistance to endocrine therapy has been a point of research. Recently, the key role of the acquisition of ligand-independent ESR1 mutation in breast cancer as a common mechanism of resistance to hormonal therapy was discovered [28].

So far, the precision medicine movement is controversial and has sparked multiple debates. On the one hand, the SHIVA trial (2015), one of the first randomized investigation of precision therapy, was negative for its primary endpoint (progression-free survival [PFS]), as no statistically significant difference in PFS between patients receiving molecularly targeted agents and the control arm was demonstrated [29]. On the other hand, studies recruiting large number of patients, such as MOSCATO 01 (2017) 
a

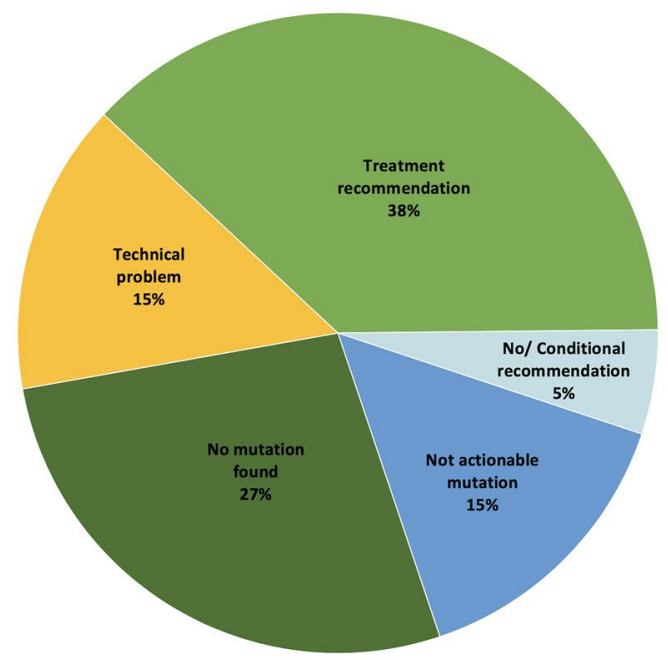

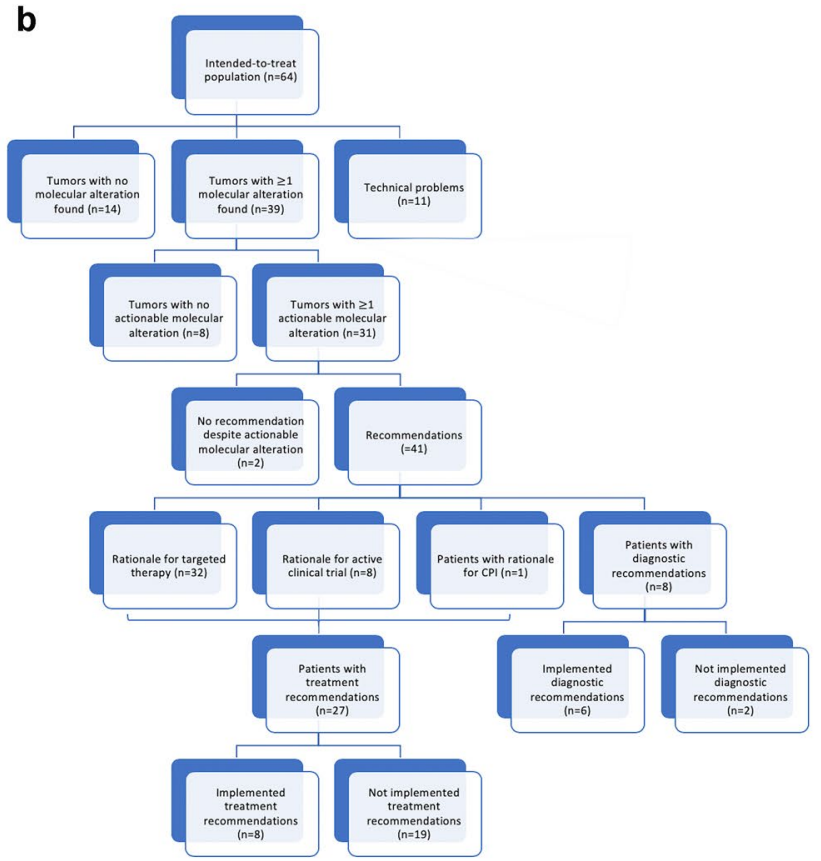

Fig. 5 Treatment or diagnostic recommendations. Note, all numbers do not add up because some patients are counted in more than one category (e.g., had an actionable alteration for a treatment recommendation and also for diagnostic recommendation or received more than

and ProfiLER (2017), suggested that high-throughput genomic analyses (i.e. next-generation sequencing, comprehensive genomic profiling) improve clinical outcome in patients with advanced cancers. However, this approach has only been proven to be beneficial to a small subset of patients so far [30, 31]. As shown in Table 4, studies focusing on precision medicine show different, contradictory results. While in some studies more than $20 \%$ of the enrolled patients received the recommended according

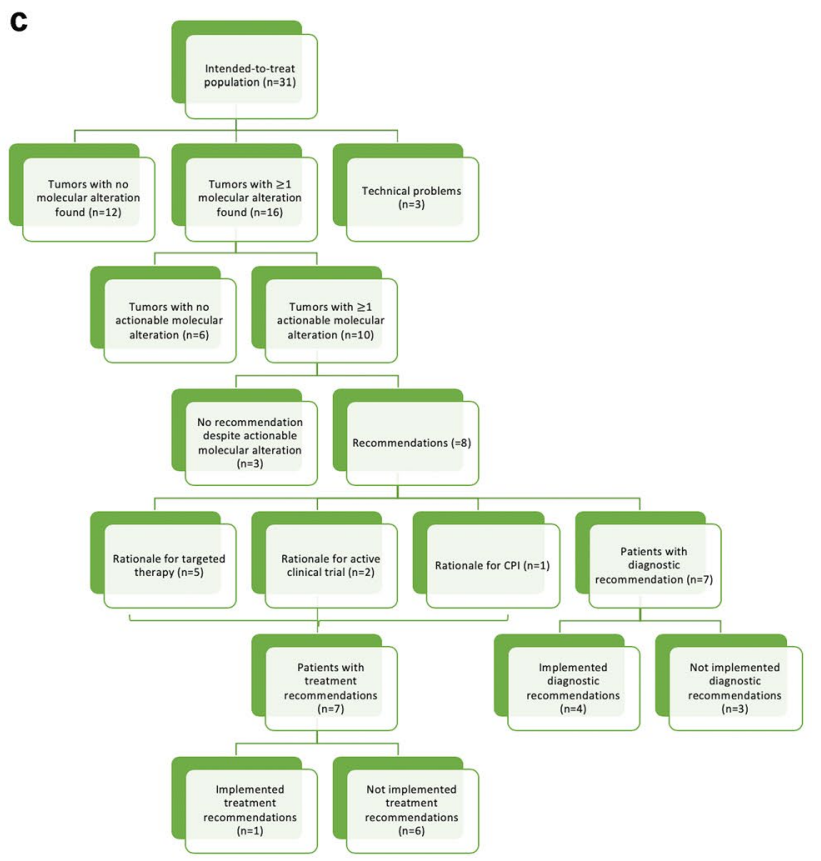

one treatment/ diagnostic recommendation). a Diagram representing the outcome of the molecular diagnostic testing $(n=95)$. b Breast cancer patients. c Gynecological cancer patients

to molecular profiling treatment, in others the number of patients treated remains very low. These results suggest the need for large data collections in order to improve selection criteria and identify markers that discriminate patients that might benefit most from precision medicine.

Although molecular targeted agents themselves are more precise than standard cytotoxic agents, clinical evidence for a significant better outcome associated with MTAs is still missing, as the access to targeted therapies remains limited, 
Table 2 Recommendations (Note, some patients received more than one diagnostic and/or treatment recommendation.)

\begin{tabular}{lll}
\hline & BC & GC \\
\hline Patients with min. 1 recommendation & No & No \\
Diagnostic & 8 & 7 \\
Therapeutic & 27 & 7 \\
No treatment recommendation & 30 & 20 \\
Conditional recommendation & 3 & 3 \\
Referral to organ board & & 1 \\
Diagnostic recommendations & & \\
Extended genetic analysis & 3 & 4 \\
PD-L1 Test & 2 & \\
HR-Status & 1 & 1 \\
Other & 5 & 3 \\
Patients with diagnostic recommendations $(n=15)$ & & \\
Implemented & 6 & 4 \\
Non-implemented & 2 & 3 \\
Treatment recommendations & & \\
Targeted therapy & 32 & 5 \\
Trial inclusion & 8 & 2 \\
Checkpoint inhibition & 1 & 1 \\
Patients with treatment recommendations $(n=36)$ & & \\
Implemented & 7 & 1 \\
Non-implemented & 22 & 6 \\
\hline
\end{tabular}

making collecting data regarding their efficacy difficult. In order to achieve their implementation in clinical care, a reassessment of the standards of evidence sufficient to prove the benefit of precision cancer therapies is needed [32]. New evidence suggests that appropriately conducted real-world data studies have the potential to support regulatory decisions in the absence of RCT data [33].

Based on initial results of the CCC LMU Munich, patients of various tumor entities benefit from extended molecular diagnostics and their implementation in clinical care [34]. Recently, many studies have described the positive effect of MTB case discussions for particular groups of patients with advanced solid cancers. However, there is not enough evidence for the utility of MTB decisions for patients with breast and gynecological malignancies.

The world of precision medicine is constantly evolving, and new targeted therapies are being developed and approved, enabling more and more patients (with up to this point of time not actionable mutation) to receive targeted therapies. For example, in spring 2019, the Food and Drug Administration of the USA (FDA) approved the PIK3CA inhibitor alpelisib in combination with endocrine therapy for patients with HR-positive, HER2-negative, PIK3CAmutated, advanced or metastatic breast cancer. The availability of this drug after start of the Managed Access Program in our clinic could have resulted in five further therapy recommendations in our MTB cohort, showing the need of identifying such alterations in cancer patients.
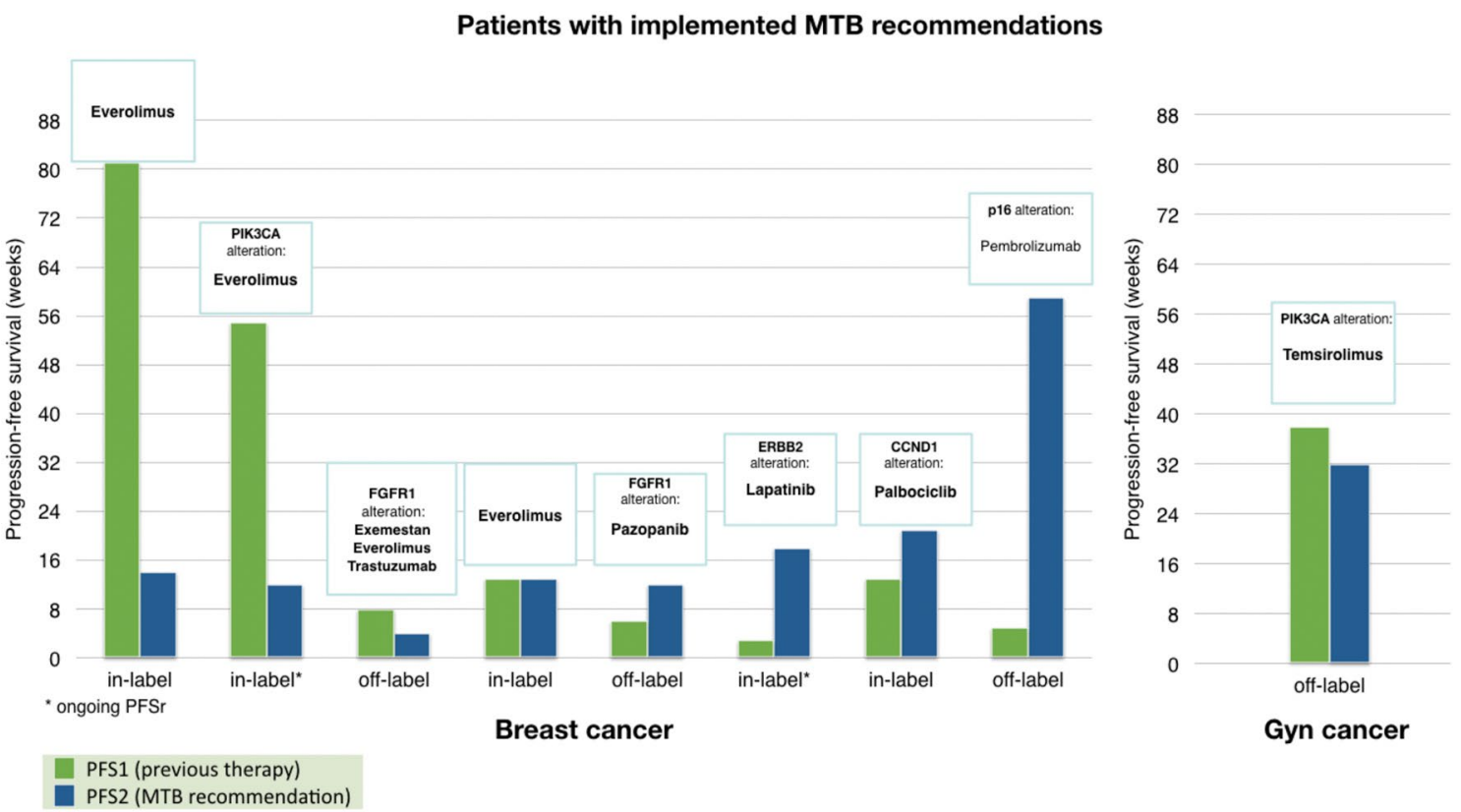

Fig. 6 Comparison of PFS of previous line of therapy (PFS1) and implemented therapy recommendation (PFS2). PFS the period of time between the start of treatment till disease progression/ death 
Table 3 PFS ratio $(\mathrm{PFSr})=$ ratio of patients' PFS on the implemented recommended therapy (PFS2) (in this case the recommended in- or off-label targeted drug) to their PFS on the most recent previous line of therapy (standard of care) (PFS1)

\begin{tabular}{llllllr}
\hline$\#$ & Tumor entity & Treatment & Label & PFS2 (weeks) & PFS1 (weeks) & PFSr \\
\hline 1 & Breast & Everolimus & In & 14 & 81 & 0.17 \\
2 & Breast & Everolimus & In & 12 & 55 & 0.22 \\
3 & Breast & Exemestan + Everoli- & Off & 4 & 8 & 0.50 \\
& & mus + Trastuzumab & & & & \\
4 & Breast & Everolimus & In & 13 & 13 & 1.00 \\
5 & Breast & Pazopanib & Off & 12 & 6 & 2.00 \\
6 & Breast & Lapatinib & In & 18 & 3 & 6.00 \\
7 & Breast & Palbociclib & In & 21 & 13 & 1.62 \\
8 & Breast & Pembrolizumab & Off & 59 & 5 & 11.80 \\
9 & Cervix & Temsirolimus & Off & 32 & 38 & 0.84 \\
\hline
\end{tabular}

PFSr PFS2/PFS1

Table 4 Overview of studies focusing on molecular profiling

\begin{tabular}{|c|c|c|c|c|c|c|}
\hline Author/Study & Tumor entity & $\begin{array}{l}\text { Enrolled } \\
\text { patients } \\
(n)\end{array}$ & MP patients & Actionable alterations & $\begin{array}{l}\text { Implemented } \\
\text { therapies- } n \text { ( } \% \text { of } \\
\text { enrolled) }\end{array}$ & Results \\
\hline $\begin{array}{l}\text { Le Tourneau et al. } \\
\text { (SHIVA) [29] }\end{array}$ & Solid tumors & 741 & $496(67 \%)$ & $293(40 \%)$ & $96(13 \%)$ & $\begin{array}{l}\text { No significant difference } \\
\text { in PFS (PFS: } 2.3 \text { vs } 2.0 \\
p=.41 \text { ), hazard ratio } \\
\text { for death or disease } \\
\text { progression, } 0.88 \text { ( } 95 \% \\
\text { CI } 0.65-1.19 \text { ) }\end{array}$ \\
\hline $\begin{array}{l}\text { Stockley et al. (IMPACT/ } \\
\text { COMPACT) [45] }\end{array}$ & Solid tumors & 1893 & $1640(87 \%)$ & $187(10 \%)$ & $84(5 \%)$ & $\begin{array}{l}\text { ORR: } 19 \% \text { in genotype- } \\
\text { matched group vs } 9 \% \\
\text { in unmatched group, } \\
p=0.61\end{array}$ \\
\hline $\begin{array}{l}\text { Massard et al. } \\
\text { (MOSCATO-01) [30] }\end{array}$ & Solid tumors & 1035 & $843(81 \%)$ & $411(40 \%)$ & $199(24 \%)$ & $\begin{array}{l}\text { ORR: } 11 \%, \text { SD } 52 \%, \\
\text { PFSr }>1.3: 63 / 193(33 \% \\
\text { of all treated patients } \\
\text { or } 7 \% \text { of all enrolled } \\
\text { patients) }\end{array}$ \\
\hline $\begin{array}{l}\text { Trédan et al. (PROFILER) } \\
\text { [31] }\end{array}$ & Solid tumors & 2579 & $1980(77 \%)$ & $1032(40 \%)$ & $163(6 \%)$ & ORR: $0.9 \%$ of all patients \\
\hline $\begin{array}{l}\text { Rodon et al. (WINTHER) } \\
\text { [46] }\end{array}$ & Solid tumors & 303 & $303(100 \%)$ & $25(89 \%)$ & $107(35 \%)$ & $\begin{array}{l}\mathrm{PFSr}>1.5: 22 \% \text { of the } \\
\text { patients with MP-based } \\
\text { treatment }\end{array}$ \\
\hline Hoefflin et al. [47] & Solid tumors & 198 & n.a & $104(53 \%)$ & $33(17 \%)$ & $\begin{array}{l}\text { PR: } 11 / 33 \text { ( } 33.3 \% \text { of all } \\
\text { treated patients or } 5.5 \% \\
\text { of all enrolled patients) } \\
\text { SD: } 8 / 33 \text { ( } 24.2 \% \text { of all } \\
\text { treated patients or } 4 \% \text { of } \\
\text { all enrolled patients) }\end{array}$ \\
\hline $\begin{array}{l}\text { André et al. (SAFIR01/ } \\
\text { UNICANCER) [21] }\end{array}$ & Breast cancer & 423 & $299(71 \%)$ & $195(46 \%)$ & $55(13 \%)$ & $\begin{array}{l}\text { ORR:4 patients had a } \\
\text { partial response and } 9 \\
\text { had SD }>16 \text { weeks ( } 3 \% \\
\text { of all patients) }\end{array}$ \\
\hline Parker et al. [27] & Breast cancer & 43 & $43(100 \%)$ & $40(93 \%)$ & $17(40 \%)$ & $\begin{array}{l}7 \text { patients ( } 41 \% \text { of all } \\
\text { treated patients or } 16 \% \\
\text { of all enrolled patients) } \\
\text { achieved SD or PR }\end{array}$ \\
\hline
\end{tabular}

$M P$ molecular profiled, $P F S$ progression-free survival, $O R R$ overall response rate, $S D$ stable disease, $P R$ disease progression, $n . a$. not available 
The rising number of active targetable mutations affects the complexity of the results, making their interpretation a challenge for many oncologists. In 2014, Gray et al. conducted a study, which evaluated cancer physicians' ability of using multiplex tumor genomic testing and showed that many physicians lack confidence in interpreting complex genomic test results as well as in incorporating them into practice [35]. Thus, we see great potential in establishing the combination of molecular diagnostic tests and a subsequent case discussion by a multidisciplinary molecular board team not only as a routine for cancer patients but also as a training platform and a knowledge-expanding approach for oncologists to help guide their decisions.

However, precision oncology faces some challenges, which delay its widespread translation into clinical practice. Critics of the incorporation of NGS and similar methods into clinical practice express following concerns:

First, the significant cost of molecular diagnostics and targeted drugs is still a great disadvantage. While prices of next-generation sequencing technologies are dropping from about $\$ 3$ billion in the year 2000 and to $\$ 5000$ today, the selection of molecular targeted agents is still enormously expensive [36]. As the price of precision medicine is still rather high for most patients, it is now crucial to also evaluate its cost-effectiveness in order to support its translation into clinical practice, for example in the setting of clinical trials and research programs [37].

Second, logistical problems causing limited access to targeted drugs and clinical trials for biomarker-positive patients represent another major problem. This is mainly due to the absence of reimbursement for drugs beyond their labelled indication. As a consequence, in order to receive the required, often off-label drug, patients need to be enrolled within active clinical trials or are required to cover the costs themselves or to file an application for reimbursement by the competent health insurance prior to treatment initiation. Clinical trials often have strict inclusion criteria and are, therefore, not easily accessible to many patients. As shown in the SAFIR01 trial, only a small number of patients benefit from personalized therapies mostly due to drug access problems. This problem could be solved by establishing a portfolio of early phase clinical basket trials or by earlyaccess-programs [38]. Recent studies suggest that the implementation of a MTB improves access to targeted therapy [39]. As seen in our clinic, the early-access-program that we started in November 2019 enabled many patients with a PIK3CA mutation to derive benefit from the targeted drug alpelisib soon after its FDA approval in spring 2019 [40].

Third, another major limitation is the testing of tumors from patients with late stage disease, which limits treatment options and hinders patients from receiving the recommended therapy or from enrolling in a clinical trial. As patients in an advanced cancer situation are often in an unstable health condition, obtaining biopsy material with a good quality of tissue is quite difficult. Our study had 14 (14.7\%) technically unsuccessful molecular diagnostics. Moreover, the time between enrolling patients in the study, processing tumor samples, followed by the molecular diagnostics and the MTB case discussion is still rather lengthy in view of the fact that malignancies in late stages tend to evolve at unprecedented speed, while causing deterioration of the general condition and hindering patients from receiving particular therapies, one of the main reasons for the relative low number of implemented therapies ( 9 out of 34). In this study, molecular profiling and discussion were completed in a clinically reasonable time frame of approximately 4 weeks, which is comparable to the median turnaround times in other studies. Therefore, it is reasonable to expect that introducing molecular profiling at an earlier time point in a patient's disease trajectory could improve the quality of molecular diagnostics and allow patients to benefit more from a multidisciplinary tailored MTB-based treatment advice.

Fourth, another concern is that the current trend of identifying single variables and matching it with an appropriate targeted therapy may be irrelevant for some patients because of the heterogeneous landscape of their cancer. Disease variability among individual tumors causes patients with tumors of similar histology to respond differently to targeted therapies [41-43]. For example, only $60 \%$ of lung cancer patients with the p.L858R mutation in the epidermal growth factor receptor gene (EGFR) respond to gefitinib, although all of them are carriers of the exact same mutation in the target gene, indicating that other, yet unknown genetic aberrations may influence the effect of targeted drugs and that the disease course is still unpredictable to a great extent [44].

Fifth, the common use of medicines outside the approved label is controversial. Off-label drug use may represent a danger for patient safety in some cases, but it is sometimes justified from a clinical point of view. Four out of nine (44\%) of the implemented recommended therapies in the study "The informative Patient" included off-label drugs; two of these patients (50\%) experienced a clinical benefit with a partial response or stabilization lasting over 4 months, while having progressed under last standard treatment.

There were several limitations to our study. First, despite a relatively high number of breast and gynecological cancer, the overall number of included patients remains low. Second, our patient cohort presented had a heterogeneous tumor type, making general conclusions relatively difficult. Third, the number of patients with implemented therapies is limited, due to deterioration of patients' general condition or no access to the recommended targeted 
drug, as previously reported in other studies. Nevertheless, we do demonstrate feasibility of and patient benefit from a routine MTB at a large comprehensive cancer center.

\section{Conclusion}

The landscape of molecular alterations in breast and gynecological cancers is heterogeneous. Advances in the quality and availability of molecular diagnostics and the number of targeted therapies increase rapidly, offering patients with advanced cancer a variety of new treatment options. MTBs try to bridge the gap in between molecular alterations and matching drugs in a structured manner.

The primary objective of the present monocentric study was to estimate, in a real-world setting, the impact of interdisciplinary MTB case discussions for patients with breast and gynecological malignancies. Altogether, on the basis of individual molecular diagnostics, diagnostic and treatment recommendations were made for 45 patients ( $47.4 \%$ of all). Nine out of 34 patients received the recommended treatment. Four out of 9 patients responded with a PFSr $>1.3$. Therefore, our results support the approach of matching specific drugs (in- and off-label) to particular genetic aberrations and demonstrate its relevance in breast and gynecological cancers for a small, but clinically relevant group of patients. By providing a multidisciplinary tailored-based treatment advice based on genetic tests, it is now possible for more patients with breast and gynecological malignancies to gain maximum clinical benefit and improve survival of patients with either advanced stage cancer or a rare tumor entity by applying personalized medicine.

The MTB strategy, however, needs to be standardized and optimized in order to eliminate major logistical problems such as limited access to targeted agents (often off-label) and clinical trials, as well as patient referral at stage disease that are too late for a beneficial therapeutic intervention.

Author contributions ES: Manuscript writing, Data management. BW: Project development, Data collection and management, Manuscript editing. AJ: Data collection, Manuscript editing. JK: Data collection, Manuscript editing. TK: Data collection, Manuscript editing. DM: Data collection, Manuscript editing. MR: Data collection, Manuscript editing. SO: Data collection, Manuscript editing. VH: Project development, Manuscript editing. KHM: Data collection, Manuscript editing. PAG: Data collection, Manuscript editing. AB: Data collection, Manuscript editing. FT: Data collection, Manuscript editing. SM: Manuscript editing, Manuscript editing. NH: Manuscript editing, Manuscript editing. RW: Project development, Data collection and management, Manuscript editing.

Funding Open Access funding enabled and organized by Projekt DEAL.

\section{Compliance with ethical standards}

Conflict of interest statement CBW received personal and speakers' fees, reimbursement for travel and accommodation and honoraria for participance in advisory boards from Bayer, Celgene, Ipsen, Rafael Pharmaceuticals, RedHill, Roche, Servier, Shire/Baxalta and Taiho and grant support by Roche. AJ received honoraria and reimbursement for travel and accommodation for participance in advisory boards and from speaker's bureau from Amgen, AstraZeneca, Biocartis, BristoMyers Squibb (BMS), Boehringer Ingelheim, Chinese Society for Pathology, German Society for Pathology, European Association for Cancer Research (EACR), International Association for Pathology (IAP), Merck-Serono, Merck-Sharp Dohme (MSD), Quality Initiative in Pathology (QuIP), Roche Pharma, Takeda; JK received honoraria and reimbursement for travel and accommodation for participance in advisory boards and from speaker's bureau from AstraZeneca, Novartis, Quality Initiative in Pathology (QuIP), Roche Pharma. TK received honoraria and reimbursement for travel and accommodation for participance in advisory boards from Amgen, AstraZeneca, Merck KGaA, MSD, Novartis, Pfizer, Roche; and from speaker's bureau from Merck and Astra Zeneca; from Merck and Roche research funding as well. KHM received honoraria from Celgene, Pfizer, Astellas, Daiichi Sankyo and Otsuka Pharma. AB received honoraria and reimbursement for travel and accommodation for participance in advisory boards from AstraZeneka, Roche and Tesaro. FT received research support, reimbursement for travel and accommodation for participance in advisory boards and from speaker's bureau from AstraZeneca, Clovis, Medac, PharmaMar, Roche, Tesaro/GSK. SM received research support, advisory board, honoraria and travel expenses from AbbVie, AstraZeneca, Clovis, Eisai, GlaxoSmithKline, Medac, MSD, Novartis, Olympus, PharmaMar, Pfizer, Roche, Sensor Kinesis, Teva, Tesaro. NH received honoraria for lectures and/or consulting from Agendia, Amgen, Astra Zeneca, BMS, Celgene, Daiichi-Sankyo, Genomic Health, Lilly, MSD, Novartis, Odonate, Pierre Fabre, Pfizer, Roche, Sandoz/Hexal, Seattle Genetics. RW received honoraria for lectures and/or consulting from Agendia, Amgen, Aristo, Astra Zeneca, Celgene, Clinsol, Daiichi-Sankyo, Eisai, Genomic Health, Glaxo Smith Kline, Hexal, Lilly, Medstrom Medical, MSD, Mundipharma, Nanostring, Novartis, Odonate, Paxman, Palleos, Pfizer, Pierre Fabre, PumaBiotechnolgogy, Riemser, Roche, Sandoz/Hexal, Seattle Genetics, Tesaro Bio, Teva.

Ethical approval The study received approval of the local ethics committee (study number: 284-10) and was performed in accordance with the ethical standards as laid down in the 1964 Declaration of Helsinki and its later amendments or comparable ethical standards.

Consent to participate and publication: Informed consent was obtained from all individual participants included in the study.

Open Access This article is licensed under a Creative Commons Attribution 4.0 International License, which permits use, sharing, adaptation, distribution and reproduction in any medium or format, as long as you give appropriate credit to the original author(s) and the source, provide a link to the Creative Commons licence, and indicate if changes were made. The images or other third party material in this article are included in the article's Creative Commons licence, unless indicated otherwise in a credit line to the material. If material is not included in the article's Creative Commons licence and your intended use is not permitted by statutory regulation or exceeds the permitted use, you will need to obtain permission directly from the copyright holder. To view a copy of this licence, visit http://creativecommons.org/licenses/by/4.0/.

\section{Appendix}

See Table 5. 
Table 5 Data supplement

\begin{tabular}{|c|c|c|c|c|c|}
\hline \# & Mutation & Tumor entity & Treatment recommended in MTB & $\begin{array}{l}\text { Followed treatment / Line of } \\
\text { therapy }\end{array}$ & $\begin{array}{l}\text { PFS (months) } \\
\text { after start of } \\
\text { treatment }\end{array}$ \\
\hline 1 & $\begin{array}{l}\text { FGFR1, androgen receptor and } \\
\text { CCND1 amplifications }\end{array}$ & Breast & $\begin{array}{l}\text { 1. CDK4/6 Inhibitor } \\
\text { 2. Everolimus 3. androgen recep- } \\
\text { tor blocker }\end{array}$ & & \\
\hline 2 & CCND1 amplification & Breast & $\begin{array}{l}\text { 1. CDK4/6 Inhibitor } \\
\text { 2. Palbociclib + Fulvestrant } \\
\text { 3. Everolimus }\end{array}$ & Palbociclib & 21 \\
\hline 3 & ERBB2 mutation & Breast & Afatinib / Neratinib & & \\
\hline 4 & PTEN deletion; MET mutation & Breast & $\begin{array}{l}\text { 1. NCT03337724 trial 2. Exemes- } \\
\tan +\text { Everolimus }\end{array}$ & & \\
\hline 5 & PIK3CA mutation & Breast & Everolimus & & \\
\hline 6 & MET Exon 14 mutation & Breast & Crizotinib & & \\
\hline 7 & $\begin{array}{l}\text { MYC, FGFR1 and CCND1 } \\
\text { amplifications }\end{array}$ & Breast & Everolimus & Everolimus & 13 \\
\hline 8 & androgen receptor amplification & Breast & $\begin{array}{l}\text { 1. NCT01945775 / } \\
\text { NCT02163694 trial } \\
\text { 2. Bicalutamide / Tamoxifen }\end{array}$ & & \\
\hline 9 & PIK3CA mutation & Breast & $\begin{array}{l}\text { 1. SOLAR-1 / IPATunity } 130 \text { trial } \\
\text { 2. Everolimus }\end{array}$ & & \\
\hline 10 & ERBB2 amplification & Breast & $\begin{array}{l}\text { Lapatinib, Trastuzumab, Emtan- } \\
\text { sine and Pertuzumab }\end{array}$ & & \\
\hline 11 & $\begin{array}{l}\text { ARID1A and PIK3CA mutations, } \\
\text { LMB }(4,16 \text { muts/MB })\end{array}$ & Breast & Everolimus & Everolimus & 12 \\
\hline 12 & $\begin{array}{l}\text { ESR1 mutation, CCND1 ampli- } \\
\text { fication }\end{array}$ & Breast & $\begin{array}{l}\text { Fulvestrant }+ \\
\text { Everolimus }\end{array}$ & & \\
\hline 13 & TP53 and NOTCH1 mutations & Breast & Cyclophosphamid & & \\
\hline 14 & $\begin{array}{l}\text { TPM3(7)—NTRK1(10) gene } \\
\text { fusion }\end{array}$ & Breast & NCT02568267 trial & & \\
\hline 15 & MET Exon 2 mutation & Breast & Cabozantinib & & \\
\hline 16 & KRAS and 2 PIK3CA mutations & Breast & $\begin{array}{l}\text { lipos. Doxorubicin / Beva- } \\
\text { cizumab + Temsirolimus/ } \\
\text { Everolimus }\end{array}$ & & \\
\hline 17 & $\begin{array}{l}\text { androgen receptor mutation, } \\
\text { PIK3CA mutation }\end{array}$ & Breast & Everolimus & & \\
\hline 18 & $\begin{array}{l}\text { FGFR1, CCND1, EGFR, } \\
\text { PIK3CA and PDGFRA ampli- } \\
\text { fications }\end{array}$ & Breast & Pazopanib & & \\
\hline 19 & ESR1 and PIK3CA mutations & Breast & $\begin{array}{l}\text { 1. NCT03056755 trial } \\
\text { 2. Everolimus }\end{array}$ & & \\
\hline 20 & $\begin{array}{l}\text { p16 high expression and MYC } \\
\text { mutation }\end{array}$ & Breast & Checkpoint inhibitor & Pembrolizumab & 59 \\
\hline 21 & androgen receptor amplification & Breast & Androgen receptor blocker & & \\
\hline 22 & AKT mutation & Breast & $\begin{array}{l}\text { 1. AKT inhibitors } \\
\text { 2. IPATunity } 130 \text { trial } \\
\text { 3. Everolimus }\end{array}$ & & \\
\hline 23 & $\begin{array}{l}\text { SLX4 and TP53 mutations; } \\
\text { amplifications: FGFR1, } \\
\text { CCND1, FGF19, FGFR3 }\end{array}$ & Breast & Pazopanib & Pazopanib & 12 \\
\hline 24 & ESR1 mutation & Breast & $\begin{array}{l}\text { Fulvestrant }+ \\
\text { CDK4/6 Inhibitoren }\end{array}$ & & \\
\hline 25 & $\begin{array}{l}\text { CCND1 and FGFR1 amplifica- } \\
\text { tions }\end{array}$ & Breast & $\begin{array}{l}\text { 1. Everolimus + antihormonal } \\
\text { therapy; } \\
\text { 2. Dovitinib }\end{array}$ & & \\
\hline 26 & $\begin{array}{l}\text { PIK3CA and ERBB2 mutations, } \\
\text { high expression ERBB2 }\end{array}$ & Breast & $\begin{array}{l}\text { 1. Pertuzumab/ Trastuzumab } \\
\text { (+ Everolimus) 2. Neratinib }\end{array}$ & Lapatinib & 18 \\
\hline
\end{tabular}


Table 5 (continued)

\begin{tabular}{|c|c|c|c|c|c|}
\hline \# & Mutation & Tumor entity & Treatment recommended in MTB & $\begin{array}{l}\text { Followed treatment / Line of } \\
\text { therapy }\end{array}$ & $\begin{array}{l}\text { PFS (months) } \\
\text { after start of } \\
\text { treatment }\end{array}$ \\
\hline 27 & FGFR1 amplification & Breast & $\begin{array}{l}\text { antihormonal therapy + Everoli- } \\
\text { mus + Trastuzumab }\end{array}$ & $\begin{array}{l}\text { Exemestan + Everolimus + Tras- } \\
\text { tuzumab }\end{array}$ & 4 \\
\hline 28 & CCND1 amplification & Breast & $\begin{array}{l}\text { 1. Exemestan + Everolimus; } \\
\text { 2. NCT-MASTER / TOP-ART } \\
\text { trial }\end{array}$ & & \\
\hline 29 & $\begin{array}{l}\text { CCND1 and FGFR1 amplifica- } \\
\text { tions }\end{array}$ & Breast & $\begin{array}{l}\text { 1. Everolimus + Exemestan } 2 . \\
\text { NCT03517956 trial }\end{array}$ & Everolimus + Exemestan & 14 \\
\hline 30 & KRAS and ERBB2 mutations & Ovary & NCT02703571 trial & & \\
\hline 31 & $\begin{array}{l}\text { ERBB2, MYC, PIK3CA ampli- } \\
\text { fications }\end{array}$ & Ovary & Everolimus + Letrozol & & \\
\hline 32 & PIK3CA alteration & Cervix & Temsirolimus & Temsirolimus & 32 \\
\hline 33 & $\begin{array}{l}\text { PIK3CA and KRAS mutations, } \\
\text { MET gene fusion }\end{array}$ & Cervix & $\begin{array}{l}\text { 1. Crizotinib } \\
\text { 2. Everolimus }\end{array}$ & & \\
\hline 34 & $\begin{array}{l}\text { KRAS, SMAD4 and PTEN } \\
\text { mutations }\end{array}$ & Endometrium & Everolimus & & \\
\hline 35 & HTB (27 muts/MB) & Other & $\begin{array}{l}\text { 1. Checkpoint inhibitor } \\
\text { 2. NCT Master trial }\end{array}$ & & \\
\hline 36 & EML4-ALK gene fusion & Other & ALK inhibitor & & \\
\hline
\end{tabular}

\section{References}

1. The Global Cancer Observatory, https://gco.iarc.fr Accessed 28 May 2020.

2. Behjati S, Tarpey PS (2013) What is next generation sequencing? Arch Dis Child Educ Pract Ed 98(6):236-238. https://doi. org/10.1136/archdischild-2013-304340

3. Kaderbhai CG, Bolidot R, Beltjens F et al (2016) Use of dedicated gene panel sequencing using next generation sequencing to improve the personalized care of lung cancer. Oncotarget 7(17):24860-24870. https://doi.org/10.18632/oncotarget.8391

4. Von Hoff DD, Stephenson JJ Jr, Rosen P et al (2010) Pilot study using molecular profiling of patients' tumors to find potential targets and select treatments for their refractory cancers. J Clin Oncol 28(33):4877-4883. https://doi.org/10.1200/JCO.2009.26.5983

5. Schwaederle M, Zhao M, Lee JJ et al (2015) Impact of precision medicine in diverse cancers: a meta-analysis of phase II clinical trials. J Clin Oncol 33(32):3817-3825. https://doi.org/10.1200/ JCO.2015.61.5997

6. Haslem DS, Chakravarty I, Fulde G et al (2018) Precision oncology in advanced cancer patients improves overall survival with lower weekly healthcare costs. Oncotarget. 9:12316-12322. https ://doi.org/10.18632/oncotarget.24384

7. Incorvati JA, Shah S, Mu Y et al (2013) Targeted therapy for HER2 positive breast cancer. J Hematol Oncol 6:38. https://doi. org/10.1186/1756-8722-6-38

8. Maekawa T, Ashihara E, Kimura S et al (2007) The Bcr-Abl tyrosine kinase inhibitor imatinib and promising new agents against Philadelphia chromosome-positive leukemias. Int J Clin Oncol 12:327-340. https://doi.org/10.1007/s10147-007-0699-1

9. Holman LL, Lu KH (2012) Genetic risk and gynecologic cancers. Hematol Oncol Clin North Am 26(1):13-29. https://doi. org/10.1016/j.hoc.2011.11.003

10. Ellsworth RE, Blackburn HL, Shriver CD et al (2017) Molecular heterogeneity in breast cancer: state of the science and implications for patient care. Semin Cell Dev Biol 64:65-72. https ://doi.org/10.1016/j.semcdb.2016.08.025

11. Salomon-Perzyński A, Salomon-Perzyńska M, Michalski B et al (2017) High-grade serous ovarian cancer: the clone wars. Arch Gynecol Obstet 295(3):569-576. https://doi.org/10.1007/s0040 4-017-4292-1

12. The Asco Post Staff (2019) Alpelisib plus Fulvestrant approved for PIK3CA mutated breast cancer. https://www.ascopost.com/ issues/june-10-2019/alpelisib-plus-fulvestrant-approved-for-pik3c a-mutated-breast-cancer/. Accessed 16 Sep 2019

13. André F, Ciruelos E, Rubovszky G et al (2019) Alpelisib for PIK3CA-mutated, hormone receptor-positive advanced breast cancer. N Engl J Med 380:1929-1940. https://doi.org/10.1056/ NEJMoa1813904

14. AGO. Alle aktuelle Empfehllungen. https://www.ago-online.de/ fileadmin/ago-online/downloads/_leitlinien/kommission_mamma /2020/Alle_aktuellen_Empfehlungen_2020.pdf. Accessed 24 April 2020.

15. Ledermann J, Harter P, Gourley C et al (2012) Olaparib Maintenance Therapy in Platinum-Sensitive Relapsed Ovarian Cancer. N Engl J Med 366:1382-1392. https://doi.org/10.1056/NEJMo a1 105535

16. Moore K, Colombo N, Scambia G et al (2018) (2018) Maintenance olaparib in patients with newly diagnosed advanced ovarian cancer. N Engl J Med 379:2495-2505. https://doi.org/10.1056/ NEJMoa1810858

17. The Asco Post (2019). Olaparib improves outcomes in ovarian cancer. https://www.ascopost.com/issues/september-25-2019/ olaparib-improves-outcomes-in-ovarian-cancer/. Accessed 29 Nov 2019

18. D'Ambrosio C, Erriquez J, Arigoni M et al (2020) (2020) PIK3R1W624R Is an Actionable Mutation in High Grade Serous Ovarian Carcinoma. Cells 9(2):442. https://doi.org/10.3390/cells 9020442

19. Zammataro L, Lopez S, Bellone S et al (2019) Whole-exome sequencing of cervical carcinomas identifies activating ERBB2 
and PIK3CA mutations as targets for combination therapy. Proc Natl Acad Sci U S A 116(45):22730-22736. https://doi. org/10.1073/pnas.191138511

20. Campbell IG, Russell SE, Choong D et al (2004) Mutation of the PIK3CA gene in ovarian and breast cancer. Cancer Res 64(21):7678-7681. https://doi.org/10.1158/0008-5472. CAN-04-2933

21. André F, Bachelot T, Commo F et al (2014) Comparative genomic hybridisation array and DNA sequencing to direct treatment of metastatic breast cancer: A multicentre, prospective trial (SAFIR01/UNICANCER). Lancet Oncol 15(3):267-274. https:// doi.org/10.1016/S1470-2045(13)70611-9

22. Oliver KE, Xiao N, Spetzler D et al (2014) The impact of tumor molecular profile-directed treatment on survival in recurrent ovarian cancer. J Clin Oncol. https://doi.org/10.1200/jco2014.32.15_ suppl.5591

23. Wang K, Li M, Hakonarson H (2010) ANNOVAR: Functional annotation of genetic variants from high throughput sequencing data. Nucleic Acids Res 38(16):e164. https://doi.org/10.1093/nar/ gkq603

24. https://www.ncbi.nlm.nih.gov/clinvar/ Accessed 20 March 2020

25. Dalton WB, Forde PM, Kang H et al (2017) Personalized medicine in the oncology clinic: implementation and outcomes of the Johns Hopkins Molecular Tumor Board. JCO Precis Oncol. https ://doi.org/10.1200/PO.16.00046

26. Jameson GS, Petricoin EF, Sachdev J et al (2014) A pilot study utilizing multi-omic molecular profiling to find potential targets and select individualized treatments for patients with previously treated metastatic breast cancer. Breast Cancer Res Treat 147(3):579-588. https://doi.org/10.1007/s10549-014-3117-1

27. Parker BA, Schwaederlé M, Scur MD et al (2015) Breast cancer experience of the molecular tumor board at the University of California, San Diego Moores Cancer Center. J Oncol Pract 11(6):442-449. https://doi.org/10.1200/JOP.2015.004127

28. Dustin D, Gu G, Fuqua SAW (2019) ESR1 mutations in breast cancer. Cancer 125:3714-3728. https://doi.org/10.1002/ cncr.32345

29. Tourneau CL, Delord JP, Gonçalves A et al (2015) Molecularly targeted therapy based on tumour molecular profiling versus conventional therapy for advanced cancer (SHIVA): a multicentre, open-label, proof-of-concept, randomised, controlled phase 2 trial. Lancet Oncol 16(13):1324-1334. https://doi.org/10.1016/S1470 -2045(15)00188-6

30. Massard C, Michiels S, Ferté C et al (2017) High-throughput genomics and clinical outcome in hard-to-treat advanced cancers: results of the MOSCATO 01 Trial. Cancer Discov 7(6):586-595. https://doi.org/10.1158/2159-8290.CD-16-1396

31. The Asco Post (2017) ProfiLER trial: routine genomic testing feasible, but only a subset of patients may benefit. https://www. ascopost.com/News/55703. Accessed 27 July 2019

32. Moscow JA, Fojo T, Schilsky RL (2018) The evidence framework for precision cancer medicine. Nat Rev Clin Oncol 15(3):183-192. https://doi.org/10.1038/nrclinonc.2017.186

33. Ramagopalan SV, Simpson A (2020) Sammon (2020) Can realworld data really replace randomised clinical trials? BMC Med. 18(1):13. https://doi.org/10.1186/s12916-019-1481-8

34. Heinrich $\mathrm{K}$, Miller-Phillips L, von Bergwelt-Baildon $\mathrm{M}$ et al (2020) The CCC LMU Molecular Tumorboard: clinical and molecular characteristics of the first 450 patients, DKK 2020. https://dkk.conference2web.com/\#! contentsessions/45052. Accessed 15 May 2020

35. Gray SW, Hicks-Courant K, Cronin A et al (2014) Physicians' attitudes about multiplex tumor genomic testing. J Clin Oncol 32(13):1317-1323. https://doi.org/10.1200/JCO.2013.52.4298

36. Schwarze K, Buchanan J, Taylor JC et al (2018) Are whole-exome and whole-genome sequencing approaches cost-effective? A systematic review of the literature. Genet Med 20:1122-1130. https ://doi.org/10.1038/gim.2017.247

37. Rody A, Ettl J, Marmé F, Prat A (2018) Molecular tumor boards. Breast Care (Basel) 13(2):141-143. https://doi.org/10.1159/00048 9138

38. Hempel D, Ebner F, Garg A et al (2020) Real world data analysis of next generation sequencing and protein expression in metastatic breast cancer patients. Sci Rep 10:10459. https://doi.org/10.1038/ s41598-020-67393-9

39. Bourien H, Lespagnol A, Campillo-Gimenez B et al (2020) Implementation of a molecular tumor board at a regional level to improve access to targeted therapy. Int J Clin Oncol 25(7):1234 1241. https://doi.org/10.1007/s10147-020-01661-6

40. Wuerstlein R, Harbeck N (2020) Präzisionsmedizin. Chancen für Forschung und Therapie. Individualisierte Diagnostik und Therapie des Mammakarzinoms: Hoffnung oder Realität? Frankfurter Forum für Gesellschafts- und Gesundheitspolitische Grundsatzfragen e.V. 40-49. http://frankfurterforum-diskurse.de/wp-conte nt/uploads/2020/04/Heft_21_Vortrag_5.pdf. Accessed 28 April 2020.

41. Seoane J, De Mattos-Arruda L (2014) The challenge of intratumour heterogeneity in precision medicine. J Intern Med. https:// doi.org/10.1111/joim. 12240

42. Burrell RA, McGranahan N, Bartek J et al (2013) The causes and consequences of genetic heterogeneity in cancer evolu- tion. Nature 501:338-345. https://doi.org/10.1038/nature12625

43. Bedard PL, Hansen AR, Ratain MJ et al (2013) Tumour heterogeneity in the clinic. Nature 501:355-364. https://doi.org/10.1038/ nature 12627

44. Sim EH, Yang IA, Wood-Baker R et al (2018) (2018) Gefitinib for advanced non-small cell lung cancer. Cochrane Database Syst Rev. 1(1):CD006847. https://doi.org/10.1002/14651858.CD006 847.pub2

45. Stockley TL, Oza AM, Berman HK et al (2016) Molecular profiling of advanced solid tumors and patient outcomes with genotypematched clinical trials: the Princess Margaret IMPACT/COMPACT trial. Genome Med 8(1):109. https://doi.org/10.1186/s1307 3-016-0364-2

46. Rodon J, Soria JC, Berger R et al (2019) Genomic and transcriptomic profiling expands precision cancer medicine: the WINTHER trial. Nat Med 25(5):751-758. https://doi.org/10.1038/ s41591-019-0424-4

47. Hoefflin R, Geißler AL, Fritsch R et al (2018) personalized clinical decision making through implementation of a molecular tumor board: a german single-center experience. JCO Precis Oncol. https ://doi.org/10.1200/PO.18.00105

Publisher's Note Springer Nature remains neutral with regard to jurisdictional claims in published maps and institutional affiliations. 